\title{
The Enlightenment of the Theory of Demand Levels on the Reform of Aerobics Courses in Colleges
}

\author{
Yu Mingrong \\ College of Physical Education, Sichuan Agricultural University, 625014
}

Keywords: Aerobics; curriculum reform; demand hierarchy theory

\begin{abstract}
The survey shows that college students' demand for aerobics courses is quite different. At present, college aerobics teaching cannot fully meet the students' demand for aerobics courses, resulting in students' evaluation of aerobics courses is not high. Based on Maslow's demand theory, students' aerobics needs are divided into credit requirements, improving physical quality requirements, improving skills needs and learning teaching methods. Through the hierarchical level of teaching content, the addition of examinations and sub-items, and the use of the "two weights and one light" group performance assessment mode to fully meet the students' needs for aerobics courses, and improve the quality of college aerobics courses.
\end{abstract}

\section{Introduction}

\subsection{College students' aerobics courses have obvious differences in demand}

Aerobics is a new type of sports that covers aesthetics, gymnastics, dance and music. It has a beautiful movement and strong sense of rhythm. It can effectively train the physical quality of college students and improve the cultivation temperament of college students. Therefore, it is widely welcomed by college students [1]. There are great differences between college students' physical quality and music quality. The comprehensive learning pressure and the awareness of aerobics have caused students to have a multi-faceted demand for aerobics courses. As shown in Figure 1, the number of students who want to exercise is $40.9 \%$ of the total number. The students with higher levels of aerobics and higher levels of demand for skills and learning methods account for $30.5 \%$ and $18.83 \%$, respectively, and the most basic needs. It is the credit requirement. College students' needs for aerobics courses have both common needs and individual needs.

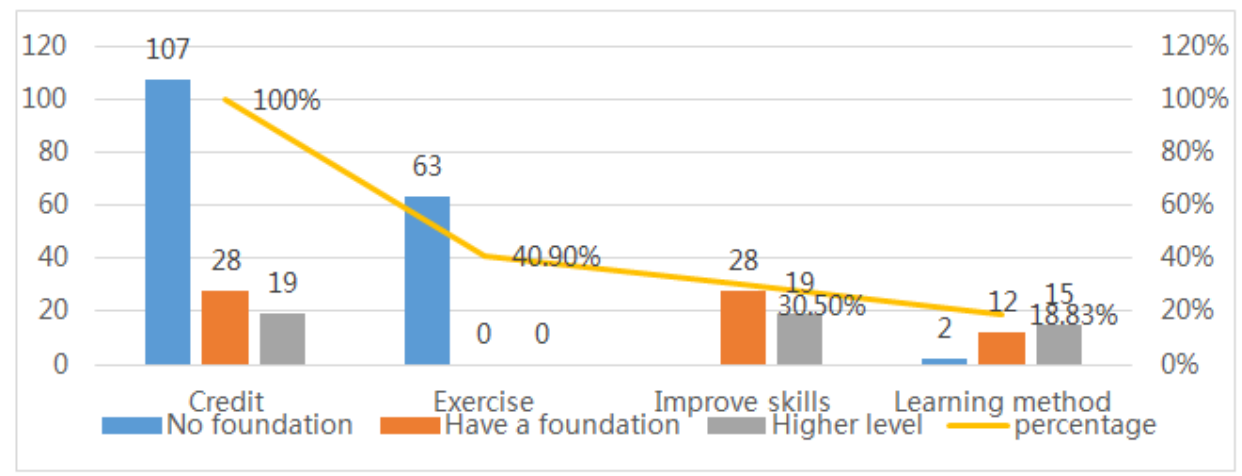

Figure 1 Survey of the needs of different basic students in aerobics courses

\subsection{Students' satisfaction rate for aerobics courses is not high}

In the survey on the satisfaction rate of aerobics courses, 21 of the 107 students without aerobics were very satisfied with the demand for aerobics courses, 69 were basically satisfied, and 17 felt less satisfied. Twelve of the students with aerobics basics felt basically satisfied, 16 were not satisfied, and 19 of the high-level ones felt that they were not satisfied. The proportion of very satisfied and basically satisfied is $59.7 \%$, the proportion of dissatisfaction is as high as $40.3 \%$, and the satisfaction rate of students without foundation is the highest, and the satisfaction rate of 
students with good foundation and foundation is significantly reduced.

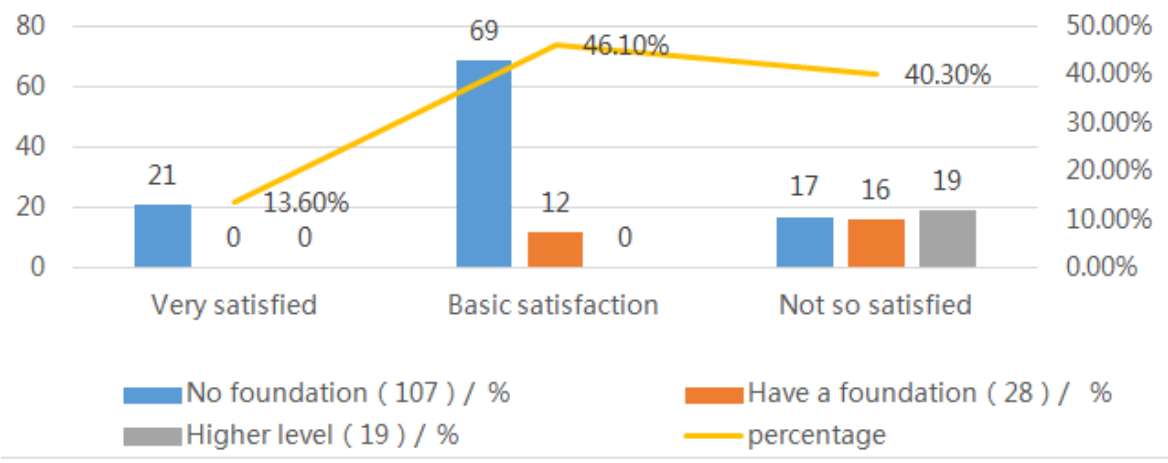

Figure 2 Student survey on aerobics curriculum needs

\subsection{Reasons for students' dissatisfaction with the demand for aerobics courses}

Students' dissatisfaction with the demand for aerobics courses is mainly concentrated in three aspects: insufficient teaching content, relatively simple teaching methods and unreasonable teaching evaluation. The dissatisfaction rate for teaching content was $63.5 \%$, and the dissatisfaction rate for teaching methods was $25 \%$. The dissatisfaction rate for teaching evaluation was $11.5 \%$.

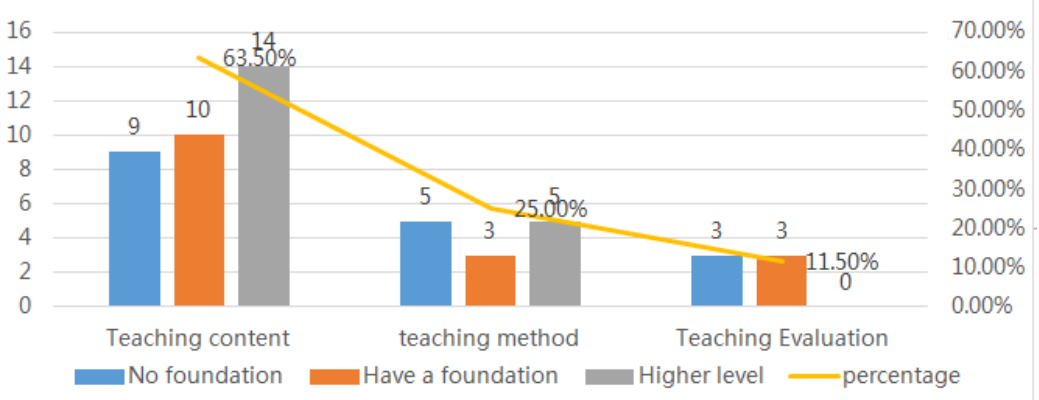

Figure 3 Survey of factors that students are dissatisfied with the demand for aerobics courses

The data shows that students with higher levels are less satisfied with the existing teaching content. The dissatisfaction rate of teaching evaluation tends to decline.

\section{The Enlightenment of the Theory of Demand Level on the Reform of Aerobics Course}

The lack of expectation of students' demand for aerobics courses is a major problem in the current aerobics courses for college sports. Maslow's demand theory reveals the types and relationships of individual demand theory, and its theory has practical significance for the reform of aerobics curriculum in colleges and universities. There is a common problem in the demand for aerobics courses for college physical education students. The survey shows that students' needs for aerobics courses have three problems. First, the needs of different basic students for aerobics courses are divided into credit requirements, skills needs and learning methods. The number of students who need skills is the highest. Second, the satisfaction of students' satisfaction with the demand for aerobics courses is not high. Third, the students' satisfaction rate for aerobics learning is not high. Students with poor foundations think that the learning content is difficult, and there are basic students and foundations. Good students feel that the teaching content is simple. According to the students' aerobics needs, they can be divided into four levels according to Maslow's demand theory, which is followed by credit needs, physical exercise needs, improvement of skill needs and learning teaching methods. The current bodybuilding is solved by satisfying the needs of students with different skill levels. The problem with the course.

\subsection{Reduce the difficulty of the prescribed combination and ensure the basic credits of students without aerobics.}

Maslow believes that breathing, water, food, sleep and gender balance are the physiological 
needs of human beings, and the lowest level of demand. If any of these needs are not met, the individual's personal physiological functions will not function properly. In other words, human life will be threatened. In this sense, physiological needs are the most important driving force for people's actions. Students' apparent "physiological needs" for aerobics are earned credits. Among the students surveyed, students who do not have aerobics basis and who are not well-coordinated or have a bad sense of music are not satisfied with the content of the teaching. Through your own best efforts, you can't complete a complete set of actions, which will make students feel conceited and anxious. Therefore, the prescribed routine is based on the 1-2 level exercise standard of the public aerobics, so that students can complete the test independently and take it smoothly.

\subsection{Implementing the "two weights and one lightness" course assessment mode to meet the students' needs for improving the aerobics assessment scores.}

At present, the evaluation method of aerobics in college sports majors is not conducive to comprehensive and objective evaluation of students' development. Therefore, colleges and universities should constantly improve their evaluation methods [3]. The "two weights and one lightness" assessment mode is a model of re-learning process and development of heavy personality and light test scores. The student's final grades are divided into two parts: the usual grades and the test scores. $70 \%$ of the total scores in the usual grades, $30 \%$ and $40 \%$ of the attendance and classroom performance respectively, and the test scores only account for $30 \%$. The student's discipline reflects the good will quality of the students. Good classroom performance is the embodiment of the students' positive attitude. Both of them reflect the good character of the students. Students who have excellent performance in normal times should be affirmed by the teachers. This is also the essence of college education in China. Adopting this assessment mode can ensure the good order and atmosphere of classroom teaching, avoid the phenomenon that the students' aerobics skill level is inconsistent and lead to the difference of students' grades, and reduce the students' dissatisfaction with the curriculum assessment.

\subsection{Scientifically and reasonably set the load to meet the needs of students to exercise.}

With the continuous advancement of the physical education curriculum reform, the physical education classroom teaching has also undergone profound changes, and the physical education classroom teaching has presented a phenomenon of blooming. However, some physical education classes emphasize the status of happy sports and the main body of students. As a result, as long as the students are happy in the physical education class, the exercise load is neglected, which directly leads to the limited functional function of the physical education class and the decline of the students' physical fitness. College aerobics courses should scientifically and reasonably arrange the exercise load, adhere to the principle of intuitiveness, the principle of starting from reality, the principle of gradual and orderly progress, the principle of consolidation and improvement, and the principle of comprehensive development of the body, improve the training adaptability level of students, and achieve the purpose of exercising physical fitness.

\subsection{The final exam for the final exam is combined with the performance of the group work to meet the student's demand for credits.}

For the prescribed routine, students need to complete the exam independently and assess their learning ability; The performance of the group's works focuses on the team's ability to collaborate and collectivism, For students with unsatisfactory scores on single-person exams or students with poor foundations, you can improve the test scores of aerobics courses through the strength of the team; For the basic students, they can be the group leader, responsible for the overall organization and coordination group's study work. After completing the group work, the team leader can get extra points and get a good workout in the process of organizing the group.

\subsection{Increasing the group study and classroom display links to enrich the teaching methods of aerobics.}

Aiming at the performance test section of the group work after the curriculum reform, the group 
learning and classroom group display sessions are added on the basis of the traditional aerobics teaching, in order to inspect and supervise the students' independent learning. Due to the difficulty of self-programming aerobics, in the process of learning, group learning can be arranged. A small number of students with poor foundations are evenly distributed to each group, and the level of aerobics is gradually improved by the help of the group. Through mutual learning, students can experience the needs of society and mutual respect in the process of learning, which not only improves the team spirit and dedication of students, but also enhances the classroom learning atmosphere. The group classroom demonstration is to let the group students show their actions after each class, which is convenient for the group to communicate and learn, and improve the quality of the group's works. After increasing the group study and classroom presentation, students will have more independent choices, which will help improve students' satisfaction with aerobics teaching.

\section{Conclusions}

People's social activities are purposeful, and people's inner needs are the driving force for social behavior. Students' learning of aerobics is no exception. Students' lack of satisfaction with the curriculum will make students slowly lose the passion and motivation of the class, resulting in poor learning atmosphere and declining teaching quality. Therefore, it is very important to fully meet the needs of students for aerobics courses. Based on Marous's demand theory, the students' aerobics needs are divided into credit requirements, skill needs and learning teaching methods from low to high. By simplifying the teaching content, paying attention to the learning process assessment, adding assessment plus points and group performance assessment. Ways to meet the needs of students of different skill levels. Under this mode of teaching, teachers should be a good guide, fully mobilize the enthusiasm of students, guide and encourage students to actively participate in learning, dare to break through self, and improve the quality of aerobics courses in sports.

\section{References}

[1] Zhao Shiqiong. On the Current Situation and Countermeasures of Teaching Contents of Aerobics Courses in Colleges and Universities [J]. Chinese Education Journal. 2015, Issue A1, P76-77

[2] Maross Hierarchy of Needs Theory [EB]. https://baike.baidu.com/item/

[3] Liu Biying, Wang Yanni. A discussion on the management motivation of female students in post-90 vocational colleges based on the hierarchy of needs [J].Culture Research.2015 (4), 91-92.

[4] Jiang Tao, Zhou Xiaofeng. Research on the Teaching Reform of College Aerobics Based on the Theory of Multiple Intelligences [J]. Education Theory and Practice. 2018, Vol. 38, No. 3, P61-62.

[5] Zhang Cuiling. Application of PBL teaching mode in college aerobics teaching [J]. Education Theory and Practice. 2017, Vol. 37, No. 27 P60-62. 